\title{
A COMPARATIVE STUDY ON THE ESTIMATION OF EXTRACTED PIGMENTS FROM SOME ALGAE USING DIFFERENT SOLVENTS
}

\author{
Abo El-Khair B. El-Sayed ${ }^{1}$, Adel F. Hamed ${ }^{2}$, Mohamed M. El-Fouly ${ }^{1}$, \\ Hesham M. Abd El Fatah ${ }^{2 *}$ and Mohamed A. Hassoub ${ }^{1}$ \\ ${ }^{1}$ Fertilization Technology Department, National Research Centre, Cairo-Dokki, \\ Egypt \\ ${ }^{2}$ Botany Department, Faculty of Science, Ain Shams University, Egypt
}

\begin{abstract}
:
Four different solvents were used to study their efficiency on pigments extraction from three different algal species of Chlorella vulgaris, Spirulina platensis and Nannochloropsis oculata. Dimethylsulfoxide, acetone, ethanol and methanol were used in the extraction process. The experiment was performed in both of fresh and oven dried algal samples. Chlorophylls $a, b$, total chlorophyll and total carotene concentrations were determined spectrophotometrically and by HPLC technique. The spectrophotometric method revealed that, dimethylsulfoxide surpasses all other used solvents in all species and all pigments in fresh samples except for chlorophyll $a$ of $N$. oculata, whereas acetone was more effective than the others in fresh and dry sample. For the dried sample of $C$. vulgaris, methanol gave the maximum extractability with chlorophyll $a$ while chlorophyll $b$ and total chlorophyll were found be maximum in dimethylsulfoxide solvent. In Spirulina, methanol represented the maximum chlorophyll $a$ and total chlorophyll for the dried samples. Total carotene was found to be higher in ethanol solvent with both $C$. vulgaris and $N$. oculata but dimethylsulfoxide surpasses the other solvents with $S$. platensis. HPLC results emphasized that, acetone surpasses all other used solvent in fresh samples and methanol was ideal solvent in dry samples of $C$. vulgaris. Dimethylsulfoxide represented the maximum chlorophyll $a$ and total carotene with Spirulina in both samples. Methanol was the best solvent for extraction of all pigments with $N$. oculata except with $\beta$-carotene of dry sample, ethanol was the best solvent.
\end{abstract}

Key words: Chlorella vulgaris, Spirulina platensis, Nannochloropsis oculata, pigments, dimethylsulfoxide, Acetone, Methanol, Ethanol, Spectrophotometer, HPLC.

\section{Introduction}

*Correspondent author: email: hesham_zaid@sci.asu.edu.eg

(ISSN: 1110-8649) 
Natural pigments have received particular attention as they have been found to exhibit various beneficial biological activities such as antioxidant, anticancer, anti-inflammatory, anti-obesity, anti-angiogenic and neuroprotective activities (Vimala and Poonghuzhali, 2015). Various natural pigments isolated from algae have attracted much attention in the fields of food, cosmetic and pharmaceutics (Pangestuti and Kim, 2011). From this perspective, investigations on carotenoids and chlorophylls are an important part of studies focused on economic applications and in research more particularly directed to ecological issues.

A wide array of solvents has been previously explored in the literature for the extraction of pigments from phototrophic organisms. The selection of the solvent to promote the extraction is a very important issue since it determines the degree of affinity to the chemical composition of the substances to be extracted (Sarkar et al., 2012).

The efficiency of plant pigment extraction generally depends on properties of the solvent, the duration of the extraction and whether mechanical disruption is used or not. Conventional extraction methods involve mechanical cell disruption like grinding (Gerloff-Elias et al., 2005) or sonication (Buchaca et al., 2005) and/or incubation in various solvents (Wright et al., 1997).

Several techniques can be used to estimate the pigments, such as: High Performance Liquid Chromatography (HPLC) pigment analysis (Cartaxana et al., 2006; Jodlowska and Latala, 2011), chlorophyll $a$ extraction and analysis by spectrophotometry (Koh et al., 2007; Ritchie, 2008). No solvent can provide complete extraction efficiency, although $90 \%$ acetone has been cited as providing a reasonable value and has been used in the majority of algal studies (Grinham $\boldsymbol{e t}$ al., 2007). In addition, the use of acetone also allows the use of accurate spectrophotometric equations (Ritchie, 2006). Nevertheless, some authors have suggested other solvents for benthic algae such as: methanol (Devesa et al., 2007) and ethanol (Ritchie, 2006).

The present study was conducted aiming for mass production of purified pigments of Chlorella vulgaris, Spirulina platensis and Nannochloropsis oculata and compares the efficiency of four different solvents for extraction capabilities of chlorophylls, phycocyanin and carotenoids form these algal species. 


\section{Materials and Methods}

\section{1-Algal samples:}

Purified strains of green alga Chlorella vulgaris Beyerinck, blue green alga Spirulina platensis (Gomont) Geitler and marine golden alga Nannochloropsis oculata (Droop) D. J. Hibberd were obtained from Algal Biotechnology Unit, Fertilization Technology Department, National Research Centre, Cairo, Egypt.

\section{2-Culture media and growth conditions:}

The selected isolates were grown under optimum conditions of BG-II nutrient solution (Stainer et al., 1971) to obtain the proper inoculum. Continuous light illumination was provided from day light lamps $(5 \mathrm{x} 40 \mathrm{w})$ reflexes from one side to give about $120 \mu$.e of light intensity. Aeration was performed by free oil compressed air from the upper hold throughout $3 \mathrm{~mm}$ polyethylene tube ended by compact sand distributor. Room temperature was recorded $\left(27 \pm 2^{\circ} \mathrm{C}\right)$ during the whole incubation period. Incubation was employed within fully transparent polyethylene bags $(75 \mathrm{~cm}$ length $\times 5 \mathrm{~cm}$ diameter and $100 \mu$ thickness) containing $2.0 \mathrm{~L}$ of the algal broth (El-Sayed and El-Fouly, 2005). When growth reached the maximum, the biomass was collected by cooling centrifuge (RUNNE HEIDBERG model RSV-20); and washed two times to remove all of the accompanied nutrients.

\section{3- Extaraction and determination of algal pigments with different solvents:}

Fresh algae $(1 \mathrm{~g})$ or dry algae $(0.5 \mathrm{~g})$ samples were used. Sample mixed with sand was put in a mortar, then solvent was added and grinding until the sample was finally colorless. The mixture was filtrated and transferred to $100 \mathrm{ml}$ measuring flask, then complete by the solvent. Chlorophyll $a$ and $b$ absorbance were measured at $666 \mathrm{~nm}$ and $645 \mathrm{~nm}$. Total carotene absorbance was measured at $468 \mathrm{~nm}$. Acetone and methanol were calculated according to (Lichtenthaler and Wellburn, 1983) for all pigments. Ethanol was calculated according to (Li et al., 2005) for chlorophyll $a, b$. Dimethylsulfoxide was calculated according to (Wellburn, 1994) for chlorophyll $a, b$. Total carotene was calculated according to (Davies, 1976) for both ethanol and dimethylsulfoxide.

Phycocyanin was extracted from the wet biomass of S. platensis. Biomass was homogenized in a mortar and pestle in the presence of acid washed neutral sand using $50 \mathrm{mM}$ sodium phosphate buffer $\mathrm{pH}$ 6.8. The biomass was obtained by 
centrifugation at $3000 \mathrm{rpm} / 5 \mathrm{~min}$ with cooling centrifuge (RUNNE HEIDBERG model RSV-20) and re-extracted with sodium phosphate buffer $\mathrm{pH} 6.8$ to ensure complete recovery of phycocyanin. Phycocyanin absorbance was measured at $615 \mathrm{~nm}$ and $652 \mathrm{~nm}$. Phycocyanin was estimated by the method of Sigelman and Kycia (1978).

Determination of chlorophyll $a$ and $\beta$-carotene was carried out by HPLC technique according to (Murray et al., 1986) and (Khalil and Varananis, 1996) respectively. For Chl. a, a Perkin Elmer LC200 HPLC pump (Perkin Elmer, Norwalk, CN, U.S.A.) series 200, attached to an C18, 250mmX4.6mmX5 $\mu \mathrm{m}$ column was used with a Perkin Elmer LC 200 fluorescence detector $(E x=431 \mathrm{~nm}$ and $\mathrm{Em}=667 \mathrm{~nm})$. Samples were on column by an injector loop (200 $\mu 1$ loop) and carried with a mobile phase of ethylacetate, methanol and water (44:49.5:6.5) flowing at $1 \mathrm{ml} / \mathrm{min}$. While for $\beta$-carotene, Sigma standard of $\beta$-carotene was used throughout the present study (Sigma, chemical company, USA). Perkin Elmer LC200 HPLC was used and carried with a mobile phase of acetonitrile, isopropanol and ethylacetate (40:40:20) flowing at $1 \mathrm{ml} / \mathrm{min}$.

\section{Results and Discussion}

Concerning the spectrophotometric results it was found that, dimethylsulfoxide (DMSO) was used as the extraction solvent to quantify the concentration of pigments, better results were obtained with the fresh samples of C. vulgaris, S. platensis and $N$. oculata for all pigments except with chlorophyll $a$ of $N$. oculata; acetone surpasses all solvents Table $(1,2,3)$. Ethanol was followed DMSO in the extraction of pigments with fresh samples of selected algae, except chlorophyll $a$ in $S$. platensis and $N$. oculata where acetone, methanol surpass all solvents respectively Table $(1,2,3)$. The lowest extraction was observed mostly for acetone with $C$. vulgaris. On contrast, the lowest extraction of others species was observed to be different according to the pigment type. For S. platensis, the lowest extraction was methanol (except ethanol and acetone with chlorophyll $a$ and carotene respectively). For $N$. oculata, dimethylsulfoxide with chlorophyll $a$ and methanol with carotene was the lowest extractants Table (1,2, $3)$.

Pigment extractions from dried samples of used algae were differed according to the type of alga, pigment and solvent. The results of $C$. vulgaris in Table (1) showed that methanol gave the highest extraction of chlorophyll $a$ 
(44.29mg.g/d.w) while, dimethylsulfoxide was the best dominant solvent in $C$. vulgaris like fresh samples with both chlorophyll $b$ and total chlorophyll. Carotene gave maximum extraction with ethanol of $34.0 \mathrm{mg} . \mathrm{g} / \mathrm{d} . \mathrm{w}$. The results of C. vulgaris showed that methanol was the lowest extractant, except ethanol with chlorophyll $a$ and acetone with total chlorophyll (Table 1). In the most results, dimethylsulfoxide was the best solvent, this may be due to it is a dipolar solvent with a tendency to accept rather than donate protons. DMSO used for chlorophyll extraction and assay, and reported as efficient when pigment concentrations are low (Wright et al., 1997). It is well known for its ability to penetrate membranes and to denature proteins reversibly by displacing or replacing the water around them. It's extremely hygroscopic and miscible with water in all proportions (Sumanta et al., 2014). Also it does not require maceration, centrifugation or filtration and it is solid at temperatures below $18{ }^{\circ} \mathrm{C}$ and re-crystallizes slowly, but is good for dealing with delicate tissues (Pompelli et al., 2013). Dimethylsulfoxide was suggested to be superior to acetone for chlorophyll $a, b$ and total chlorophyll for freshwater green algae (Shoaf and Lium, 1976) and for brown algae (Vimala and Poonghuzhali, 2015). However, acetone extraction of pigments was more efficient in green and red algae than DMSO extraction (Vimala and Poonghuzhali, 2015).

For S. platensis, methanol surpasses all other used solvents in all pigments extraction except with carotene; dimethylsulfoxide gave the highest extraction efficiency of $9.54 \mathrm{mg} . \mathrm{g} / \mathrm{d} . \mathrm{w}$. The lowest extraction was observed with acetone (except ethanol with chlorophyll $a$ ) (Table 2). Methanol results with Spirulina dry samples gave maximum value; these results were in harmony with (Hasni et al., 2011) who reported that methanol has been reported to be more efficient than acetone. Methanol removed 20\% more pigment than acetone (90\%) when tissue grinding was performed.

For $N$. oculata, like fresh sample, chlorophyll $a$ was highly extracted and purified using acetone, while, ethanol surpasses all other solvents in carotene extraction. On contrast, the lowest value was observed with dimethylsulfoxide (Table 3). Kumar et al., (2009) reported that chlorophyll (Chl. $a, b$ and total chlorophyll) content extracted using acetone shot up in species of Chlorophyta followed by Rhodophyta. Carotenoid content was recorded greater in the members of Rhodophyta than Chlorophyta. 
Table (1): Pigments fraction of fresh and dried Chlorella vulgaris biomass using as different solvents

\begin{tabular}{|c|c|c|c|c|c|c|c|c|}
\hline & \multicolumn{6}{|c|}{ Chlorella vulgaris (Dry weight=19.44g/100g) } \\
\hline & \multicolumn{3}{|c|}{ Fresh samples (mg.g/d.w.) } & \multicolumn{4}{c|}{ Dry samples (mg.g/d.w.) } \\
\hline & Acetone & Methanol & Ethanol & DMSO & Acetone & Methanol & Ethanol & DMSO \\
\hline Chl. $a$ & 12.00 & 20.30 & 24.21 & 27.73 & 11.30 & 44.29 & 4.250 & 16.84 \\
\hline Chl. $b$ & 23.45 & 31.45 & 60.35 & 70.03 & 14.74 & 9.620 & 32.96 & 38.12 \\
\hline Total Chl. & 35.45 & 51.75 & 84.56 & 97.76 & 26.04 & 53.91 & 37.21 & 54.96 \\
\hline Carotene & 4.500 & 7.600 & 7.72 & 24.3 & 31.00 & 7.000 & 34.00 & 20.92 \\
\hline
\end{tabular}

Table (2): Pigments fraction of fresh and dried Spirulina platensis biomass using as different solvents

\begin{tabular}{|c|c|c|c|c|c|c|c|c|}
\hline & \multicolumn{4}{|c|}{ Spirulina platensis (Dry weight= 17.74g/100g) } \\
\hline & \multicolumn{4}{|c|}{ Fresh samples (mg.g/d.w.) } & \multicolumn{4}{c|}{ Dry samples (mg.g/d.w.) } \\
\hline & Acetone & Methanol & Ethanol & DMSO & Acetone & Methanol & Ethanol & DMSO \\
\hline Chl. $a$ & 8.700 & 7.790 & 7.078 & 27.46 & 16.60 & 39.67 & 16.37 & 23.41 \\
\hline Total Chl. & 28.53 & 15.53 & 32.53 & 91.26 & 35.85 & 106.1 & 64.55 & 71.77 \\
\hline Carotene & 1.100 & 1.500 & 2.900 & 2.97 & 1.900 & 8.800 & 8.000 & 9.54 \\
\hline
\end{tabular}

Table (3): Pigments fraction of fresh and dried Nannochloropsis oculata biomass using as different solvents

\begin{tabular}{|c|c|c|c|c|c|c|c|c|}
\hline & \multicolumn{8}{|c|}{ Nannochloropsis oculata (Dry weight $=15.21 \mathrm{~g} / 100 \mathrm{~g}$ ) } \\
\hline & \multicolumn{4}{|c|}{ Fresh samples (mg.g/d.w.) } & \multicolumn{4}{|c|}{ Dry samples (mg.g/d.w.) } \\
\hline & Acetone & Methanol & Ethanol & DMSO & Acetone & Methanol & Ethanol & DMSO \\
\hline Chl. $a$ & 61.70 & 31.10 & 20.60 & 19.33 & 138.4 & 116.9 & 21.90 & 17.20 \\
\hline Carotene & 6.200 & 5.800 & 12.86 & 14.49 & 9.800 & 10.60 & 19.74 & 3.879 \\
\hline
\end{tabular}

Phycocyanin was extracted from $S$. platensis; the results that obtained from extraction of both dry and fresh sample (Fig. 1) were 4.23, 2.03mg.g, respectively. Phycocyanin results are superior to those reported by (Abalde et al., 1998) obtaining a phycocyanin concentration from Synechococcus sp. IO201 of $27 \mathrm{~g} \mathrm{~mL}^{-1}$, and (Minkova et al., 2003) extracting C-phycocyanin from fresh biomass of $S$. fusiformis of $1.28 \mathrm{mg} \mathrm{mL}^{-1}$. Gantt, (1981) reported that the phycocyanin extracted from dried samples also showed variations in spectra when compared to phycocyanin from fresh biomass. The phycocyanin sample extracted from fresh biomass showed a major peak at $615 \mathrm{~nm}$ while that extracted from dried samples showed an additional peak at $652 \mathrm{~nm}$. The significant loss of phycocyanin in dried samples could be due to its peripheral position in phycobilisomes on the thylakoid membrane and attributable to its

Egyptian J. of Phycol. Vol. 17, $2016 \quad$ - 6 - 
sensitivity to temperature. Sarada et al., (1999) reported that the sample extracted by homogenisation showed a minor second peak at $615 \mathrm{~nm}$ and $652 \mathrm{~nm}$ indicating the contamination of chlorophyll which is due to disintegration of cells. For extraction of phycocyanin in small samples, homogenization in mortar and pestle would be ideal procedures to follow.

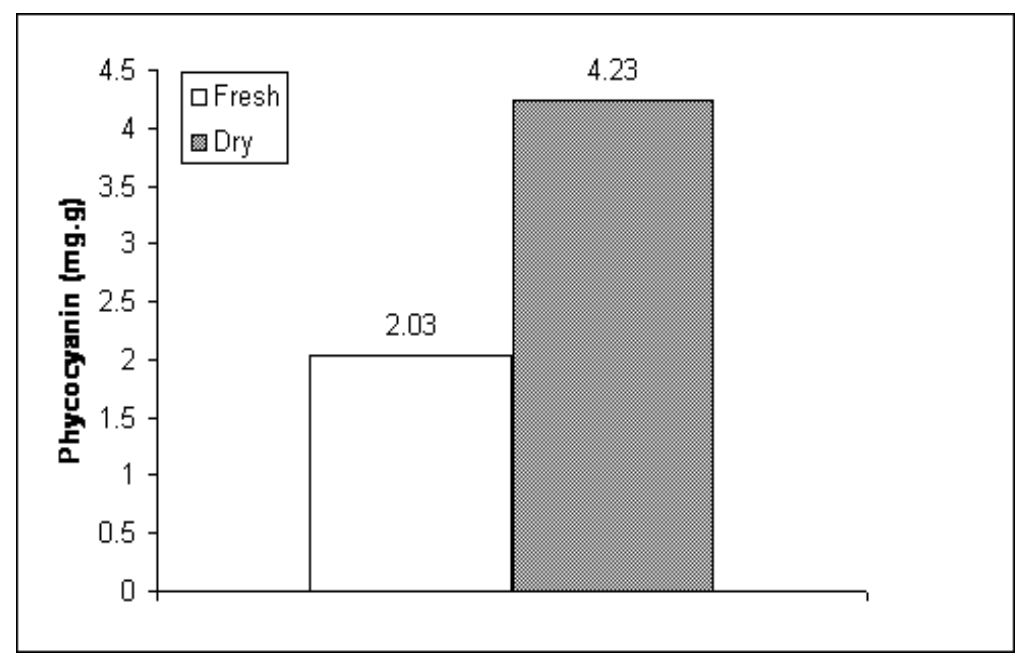

Fig. (1) Phycocyanin extraction of Spirulina platensis

HPLC results emphasized that, in $C$. vulgaris, acetone was the best solvent for extraction of chlorophyll $a$ and $\beta$-carotene with highest absorbance peak of wet samples. While, in dry samples methanol was found to be maximum extractant for both pigments. The lowest result of $C$. vulgaris was differed according to the solvent type, with chlorophyll $a$, dimethylsulfoxide was the lowest extractant in wet sample and acetone in dry sample. For $\beta$-carotene, ethanol was the lowest in both samples (Figs. $2 \& 3$ ). In $S$. platensis, dimethylsulfoxide surpasses all other used solvents with both fresh and dry samples. Ethanol was found to be the minimum extractant with all pigments except with $\beta$-carotene where, acetone was the lowest one (Figs. $4 \& 5$ ). Methanol was the better solvent than the others with both fresh and dry samples of $N$. oculata except with $\beta$-carotene dry sample; ethanol was the highest extractant. On contrast, the lowest extraction in all pigments was observed for dimethylsulfoxide (Figs. $6 \& 7$ ). 
Acetone solvent gives very sharp chlorophyll absorption peaks but acetone is sometimes a poor extractant of chlorophyll from some algae, particularly green algae. Acetone is known to have a lower extractability of chlorophylls from the protein matrix (Nakamura and Watanabe, 2001). Unfortunately, the Chl. absorption peaks are generally broader and lower in methanol and ethanol. The peaks for Chl. $b$ and Chl. $c$ are not only lower and broader in methanol and ethanol, the widened peak of Chl. $a$ in these solvents tends to interfere more strongly with the absorbance of the other Chlorophylls (Ritchie, 2006). Dimethylsulfoxide was as effective as acetone, methanol and ethanol for the diatoms, blue-green algae and green algae tested (Strain and Svec, 1966). The positive results of methanol may be agreement with (Simon and Helliwell, 1998) who found methanol and ethanol to be superior extraction solvents to acetone. Sartory and Grobbelaar (1984) similarly found that $90 \%$ acetone was an inefficient organic solvent compared to methanol or 95\% ethanol. However, it has been shown that the use of methanol as an extraction solvent resulted in an unstable solution and lead to the formation of chlorophyll $a$ degradation products (Jeffrey et al., 1997). Although 100\% acetone was found not to yield the highest amount of chlorophyll for many particular species, its use as an extracting solvent strongly inhibited the formation of degradation products (Jeffrey et al., 1997).

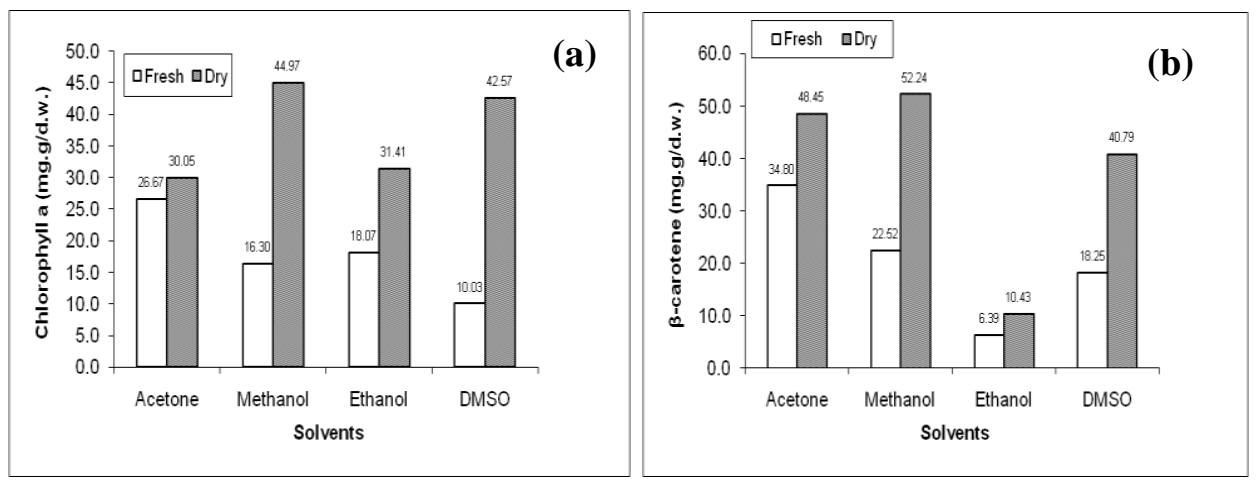

Fig. (2): (a) Chlorophyll $a$, (b) $\beta$-carotene of fresh and dry samples of Chlorella vulgaris biomass using different solvents by HPLC 


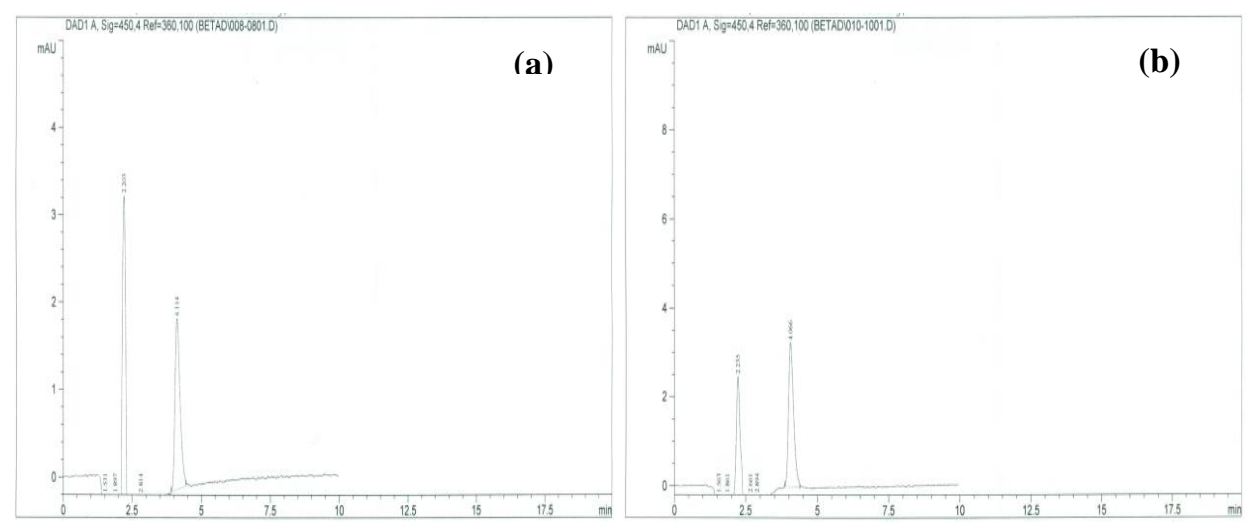

Fig. (3). HPLC chromatogram of (a) chlorophyll $a$ and (b) $\beta$-carotene extract from Chlorella vulgari
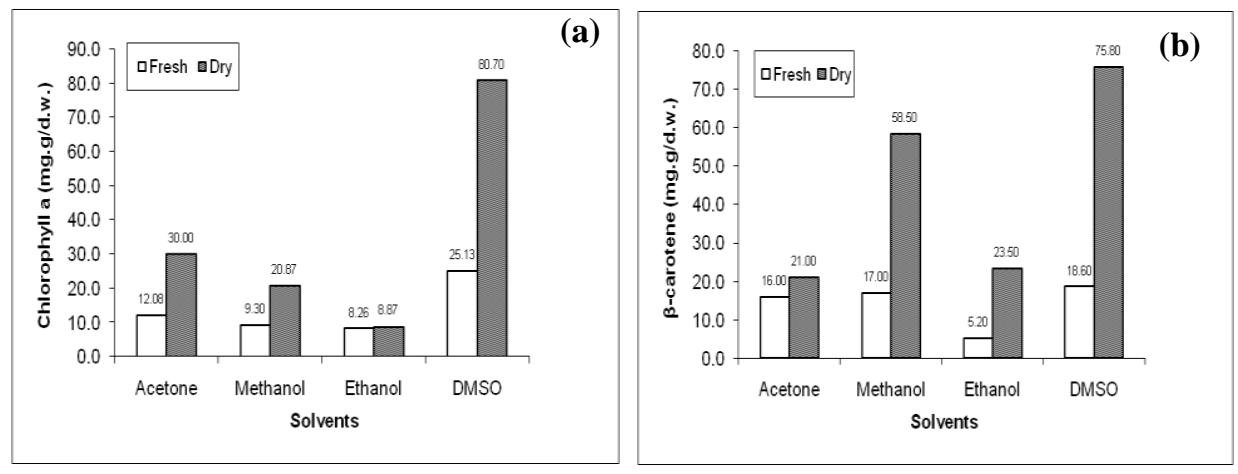

Fig. (4) (a) Chlorophyll $a$, (b) $\beta$-carotene of fresh and dry samples of Spirulina platensis biomass using different solvents by HPLC 


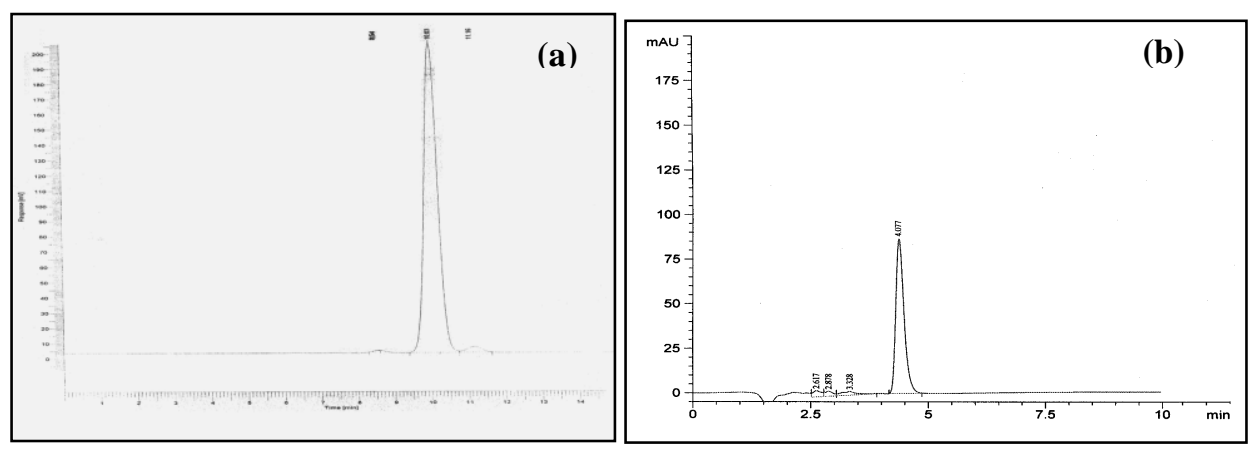

Fig. (5). HPLC chromatogram of (a) chlorophyll $a$ and (b) $\beta$-carotene extract from Spirulina platensis
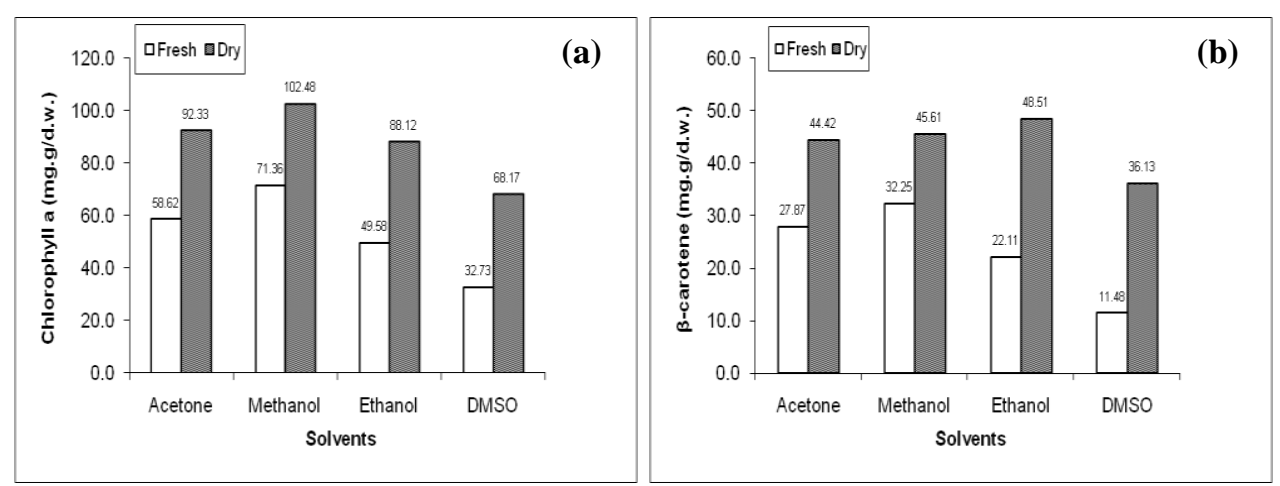

Fig. (6) (a) Chlorophyll a and (b) $\beta$-carotene of fresh and dry samples of Nannochloropsis oculata biomass using different solvents by HPLC 


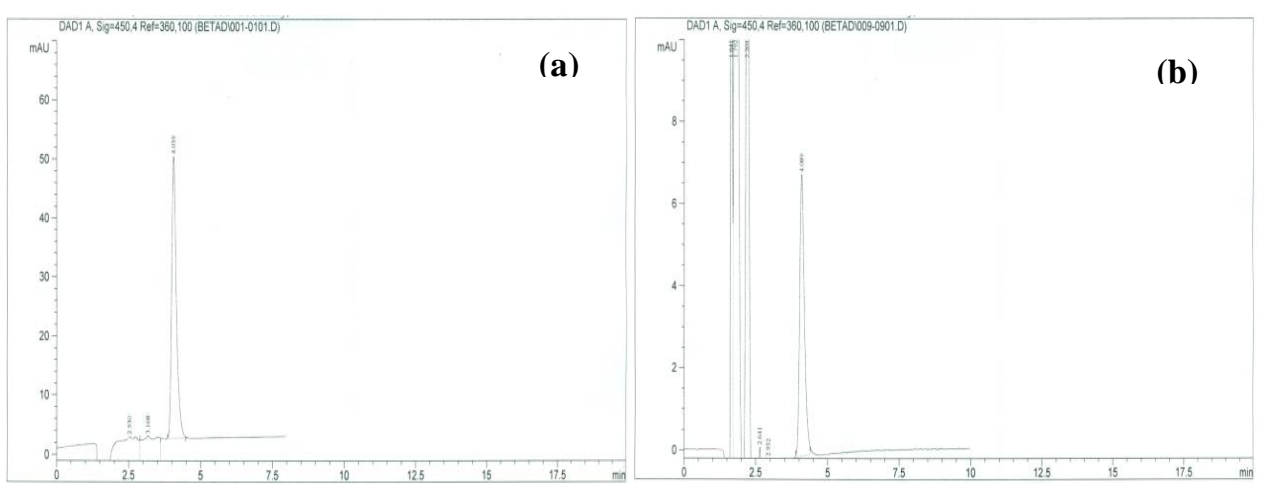

Fig. (7). HPLC chromatogram of chlorophyll $a$ and $\beta$-carotene extract from Nannochloropsis oculata

\section{Conclusion}

Spectrophotometrically, dimethylsulfoxide considered as the best extraction solvent used in pigments evaluation from microalgae biomass of wet and dry samples. Dimethylsulfoxide showed to be better than acetone, methanol and ethanol. Methanol and acetone were coming in the second position of the extraction efficiency. Both of them showed to be better than ethanol, which is not very efficient in the extraction of pigments.

For extraction of phycocyanin, homogenization in mortar and pestle would be ideal procedures and dry sample is more affected than fresh sample.

With HPLC technique, acetone and methanol of were the best solvents in case of $C$. vulgaris in wet and dry samples, respectively. While, dimethylsulfoxide with $S$. platensis and methanol with $N$. oculata, both of them showed to be better than other used solvents. 


\section{References}

Abalde, J., Betancourt, L., Torres, E., Cid, A. and Barwell, C. (1998). Purification and characterization of phycocyanin from the marine cyanobacterium Synechococcus sp. IO9201. Plant Science, 136:109-120.

Buchaca, T., Felip M. and Catalan, J. (2005). A comparison of HPLC pigment analyses and biovolume estimates of phytoplankton groups in an oligotrophic lake. J. Plankton Res.; 27:91-101.

Cartaxana, P., Mendesm C., Van Leeuwe, M. and Brotas, V. (2006). Comparative study on the microphytobenthic pigments of muddy and sandy intertidal pigments of the Tagus estuary. Est. Coast. Shelf Sci.; 66:225-230.

Davies, H. (1976). Carotenoids. In Chemistry and Biochemistry of Plant Pigments. $2^{\text {nd }}$ Eddition Goodwin. T. W. Academic Press, 2:38-165.

Devesa, R., Moldes, A., Díaz-Fierros, F. and Barral, M. (2007). Extraction study of algal of algal pigments in river bed sediments by applying factorial designs. Talanta, 72:1546-1551.

El-Sayed, A. B. and El Fouly, M. M. (2005). Recovery of outdoor mass culture bleached Scendesmus sp. Pakistan journal of biological science, 8(3):470474.

Gantt, E. (1981). Phycobilisomes. Ann. Rev. Plant Physiol.; 32:327-47.

Gerloff-Elias, A., Spijkerman, E. and Schubert, H. (2005). Light acclimation of Chlamydomonas acidophila accumulating in the hypolimnion of an acidic lake (pH 2.6). Freshwater Biol.; 50:1301-1314.

Grinham, A., Carruthers, T., Fisher, P., Udy, J. and Dinnison, W. (2007). Accurately measuring the abundance of benthic microalgae in spatially variable habitats. Limnol. Oceanogr. Methods, 5:119-125.

Hasni, Z., Yaacob, J. S., Yusoff, A. I. M., Taha, R. M., Yahya, R., Bakrudeen, A. Ahmed, A. and Ramesh, K. (2011). Effect of different solvents extraction on recovery of pigments in Xylocarpus granatum, endangered medicinal plant Materials Research Innovations, 15(2):1-4. 
Jeffrey, S. W., Mantoura, R. F. C. and Bjørnland, T. (1997). Data for the identification of 47 key phytoplankton pigments. - In: Jeffrey, S.W., Mantoura, R.F.C., Wright, S.W. (ed.): Phytoplankton pigments in oceanography: Guidelines to modern methods, 449-559.

Khalil, I. A. and F. R. Varananis. (1996). Carotenoid extraction and analysis by reversed phase HPLC system. Sarhad J. Agric.; 105(67): 15-21.

Koh, C., Khim, J., Araki, H., Yamanishi, H. and Koga, K. (2007). Within-day and seasonal patterns of microphytobenthos biomass determined by comeasuremen of sediment and water column chlorophylls in the intertidal mudflat of Nanaura Sea, Ariake Sea, Japan. Est.Coast. Shelf Sci.; 72:4252.

Kumar, N. J. I.; Kumar, R. N., Bora, A.; Kaur Amb, M. and Chakraborthy, S. (2009). An Evaluation of the Pigment Composition of Eighteen Marine Macroalgae Collected from Okha Coast, Gulf of Kutch, India, Our Nature; 7:48-55.

Li, D. X., Guo, Y. X., Yun, H. Y., Zhang, M., Gong, X. Y. and Mu., F. (2005). Methods of chlorophyll determination from maize (in Chinese, with English abstract). Chin. Agri. Sci. Bull.; 21:153-155.

Lichtenthaler, H. K., Wellburn, A. R. (1983). Determination of total carotenoids and chlorophylls a and $\mathrm{b}$ of leaf in different solvents. Biol. Soc. Trans.; 11:591-592.

Jodłowska, S. and Latala, A. (2011). The comparison of spectrophotometric method and high performance liquid chromatography in photosynthetic pigments analysis. Online Journal of Biological Sciences, 11: 63-69.

Minkova, K. M., Tchernov, A. A., Tchorbadjieva, M. I., Fournadjieva, S. T., Antova, R. E. and Busheva, M. C. (2003). Purification of Cphycocyanin from Spirulina (Arthrospira) fusiformis. J. Biotechnol.; 102:55-59.

Murray, A. P., Gibbs, C. F., Shiroyama, A. R. and Flett, D. J. (1986). Determination of chlorophyll in marine waters: intercomparison of a rapid HPLC method with full HPLC, spectrophotometric and fluorometric methods. Mar. Chem.; 19:211-227.

Nakamura, A. and Watanabe, T. (2001). Separation and determination of minor photosynthetic pigments by reversed-phase HPLC with minimal alteration of chlorophylls. Anal. Sci., 17: 503-508. 
Pangestuti, R., and Kim, S-K. (2011). Biological activities and health benefit effects of natural pigments derived from marine algae, J. Func. Food., 3(4), 255-266.

Pompelli, M. F.; França,S. C.; Tigre, R. C.; de Oliveira, M. T.; Sacilot, M. and Pereira, E. C. (2013). Spectrophotometric determinations of chloroplastidic pigments in acetone, ethanol and dimethylsulphoxide. R. bras. Bioci., Porto Alegre, 11(1), 52-58.

Ritchie, R. J. (2006). Consistent sets of spectrophotometric chlorophyll equations for acetone, methanol and ethanol solvents. Photosynth. Res.; 89:27-41.

Ritchie, R. J. (2008). Universal chlorophyll equations for estimating chlorophylls $a, b, c$, and $d$ and total chlorophylls in natural assemblages of photosynthetic organisms using acetone, methanol, or ethanol solvents. Photosynthetica, 46: 115-126.

Sarada, R., Pillai, M. G. and Ravishankar, G. A. (1999). Phycocyanin from Spirulina sp: influence of processing of biomass on phycocyanin yield, analysis of efficacy of extraction methods and stability studies on phycocyanin. Process Biochemistry, 34:795-801

Sarkar, C. R. ; Das, L.; Bhagawati, B. and Goswami, B. Ch. (2012). A comparative study of carotenoid extraction from algae in different solvent systems Asian Journal of Plant Science and Research, 2 (4):546-549.

Sartory, D. P. and Grobbelaar, J. E. (1984). Extraction of chlorophyll a from freshwater phytoplankton for spectrophotometric analysis. Hydrobiol.; 114:177-187.

Shoaf, T. W. and Lium, B. W. (1976). Improved extraction of chlorophyll a and b from algae using dimethylsulphoxide. Limnol Oceanogr.; 21: 926-928.

Sigelman, H. W. and Kycia, J. H. (1978). Algal biliproteins. In: Hellebust JA, Craigie JS, editors. Handbook of Phycological Methods. Cam-bridge: Cambridge University Press, 72-81.

Simon D. and Helliwell, S. (1985). Extraction and quantification of chlorophyll a from freshwater green algae. Water Research, 32, 7: 2220-2223.

Stainer, R. Y., Kunisawa, R., Mandel, M. and Cohin-Bazire, G. (1971). Purification and properties of unicellular blue-green algae (order Chrococcales). Bacteriol. Rev.; 35:171-205. 
Strain, H. H. and Svec. W. A. (1966). Extraction, separation, estimation and isolation of chlorophylls. In L. P. Vernon and G. R. Seeley [eds.], The chlorophylls. Academic. 21-66.

Sumanta, N.; Haque, I. C.; Nishika, J. and Suprakash, R. (2014). Spectrophotometric analysis of chlorophylls and carotenoids from commonly grown fern species by using various extracting solvents. Research Journal of Chemical Sciences, 4(9), 63-69.

Vimala, T. and Poonghuzhali, T. V. (2015). Estimation of pigments from seaweeds by using acetone and DMSO. International Journal of Science and Research, 4 (10), 1850-1854.

Wellburn, AR. (1994). The spectral determination of chlorophylls $a$ and b, as well as total carotenoids, using various solvents with spectrophotometers of different resolution. J. Plant Physiol.; 144:307-313.

Wright, S. W., Jeffrey, S. W. and Mantoura, F. R. C. (1997). Evaluation of methods and solvents for pigment extraction. In: Jeffrey, S.W., Mantoura, R.F.C., Wright, S.W. (eds.): Phytoplankton pigments in oceanography: Guidelines to Modern Methods, 261-282. 


\section{دراسة مقارنة على تقدير الأصباغ المستخرجة من بعض الطحالب باستخدام مذيبات مختثفة}

أبو الخير بدوى السيد'، عادل فهمى حامد '، محمد مصطفى الفولى' ، هشام محمد عبد الفتاح'،

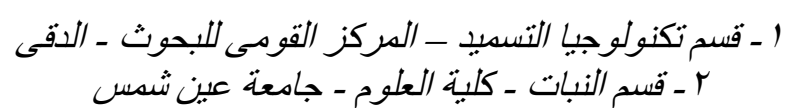

تم إستخدام أربعة مذيبات مختلفة لدراسة كفاءة الاستخلاص على استخراج الصبغات من ثلاثة

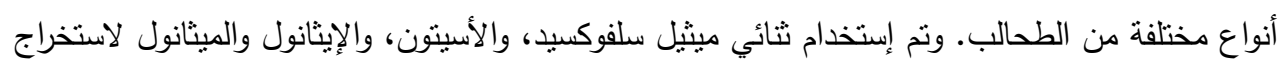
الأصباغ من الطحالب Sannochloropsis و Spirulina platensis , Chlorella vulgaris oculata

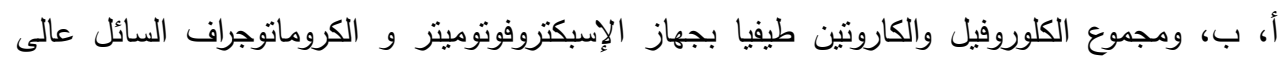

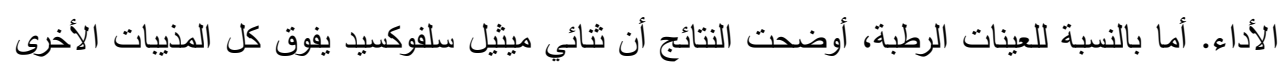

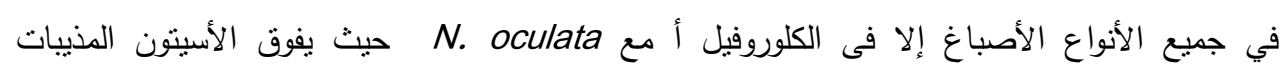

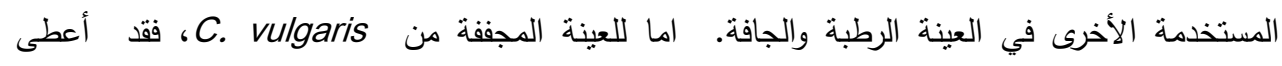

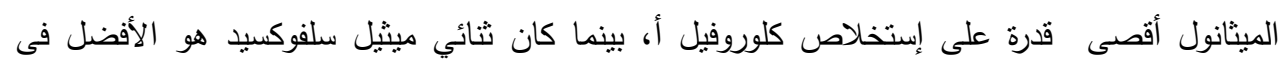

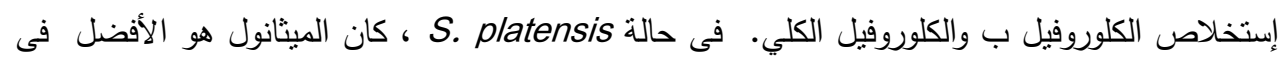

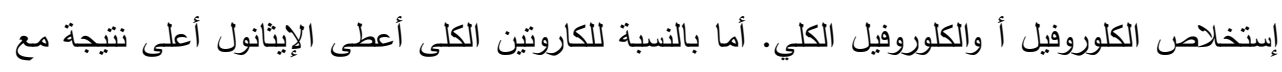

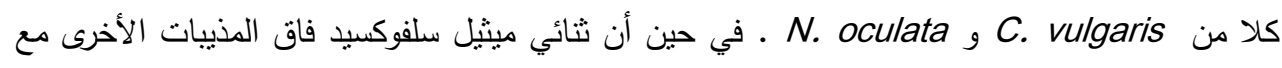
S. platensis

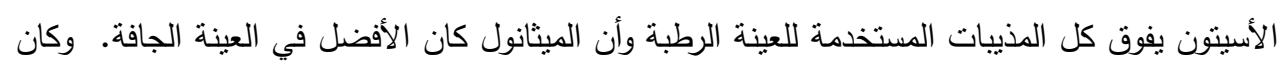

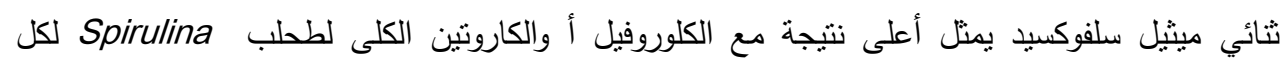

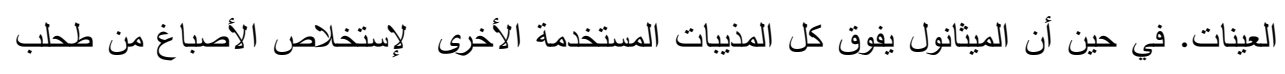
N oculata 